\title{
"Snapping" of the extensor carpi ulnaris tendon in asymptomatic population
}

\author{
Firat Erpala ${ }^{1 *}$ (D) and Tahir Ozturk ${ }^{2}$ (D)
}

\begin{abstract}
Background: Extensor carpi ulnaris tendinopathy (ECU) can be one cause of ulnar side wrist pain and it is more prominent in pronation-supination movements against resistance. In supination, flexion, and ulnar deviation within the ulnar groove, the tendon is tense and becomes predisposed to subluxation or dislocation. Snapping occurs during this dislocation and relocation. As a result of this friction between the tendon sheath and ulnar groove, tendinopathy and pain occur. ECU tendon is an important structure that contributes to the dynamic stability of wrist therefore resulting degeneration contributes disruption of distal radioulnar joint and causes wrist instability.

Methods: Participants without active wrist complaints who presented to the outpatient clinic between 2019 and 2020 were included. Provocation test was performed and participants with snapping were evaluated with ultrasound to determine subluxation or dislocation. Participants asked to indicate approximately how much time they spent daily on the phone, computer and game console. The distribution of data was evaluated with the Kolmogorov-Smirnov test. Quantitative data that were not normally distributed were evaluated using the MannWhitney $U$ test, and Student's t-test was used for normally distributed data. The Chi-square test was used to compare categorical variables. For all tests, $p<0.05$ was considered statistically significant.

Results: Four hundred and fifteen women and 340 men were included in the study. Fifty of the 755 participants (6.6\%) had snapping. 22 of the 755 participants (2.9\%) had dislocation or subluxation on ultrasound. Three (13.6\%) participants had dislocation and 19 (\%86.4) participants had subluxation on ultrasound. All 50 of the participants with snapping had significant repetitive trauma and sports activities. It was determined that 21 of the 22 participants who were found to have subluxation or dislocation by ultrasound had more than two hours of hobby activity and significantly more participants had more than two hours of activity compared to the group without subluxation or dislocation.
\end{abstract}

Conclusions: This study with a large number of participants will contribute to the literature in terms of evaluating the contribution of technological devices, such as computers, smartphones, and consoles to chronic wrist pain and the prevalence of ECU snapping in the asymptomatic population.

Trial registration: Date of Approval; 19.02.2019, Approval Number; 19-KAEK-045.

Keywords: Extensor carpi ulnaris, Tendinopathy, Snapping ECU

* Correspondence: drfiraterpala@hotmail.com

'Department of Orthopaedics and Traumatology, Cesme Alpercizgenakat State Hospital, 35930 Izmir, Turkey

Full list of author information is available at the end of the article

(c) The Author(s). 2021 Open Access This article is licensed under a Creative Commons Attribution 4.0 International License, which permits use, sharing, adaptation, distribution and reproduction in any medium or format, as long as you give appropriate credit to the original author(s) and the source, provide a link to the Creative Commons licence, and indicate if changes were made. The images or other third party material in this article are included in the article's Creative Commons licence, unless indicated otherwise in a credit line to the material. If material is not included in the article's Creative Commons licence and your intended use is not permitted by statutory regulation or exceeds the permitted use, you will need to obtain permission directly from the copyright holder. To view a copy of this licence, visit http://creativecommons.org/licenses/by/4.0/. The Creative Commons Public Domain Dedication waiver (http://creativecommons.org/publicdomain/zero/1.0/) applies to the data made available in this article, unless otherwise stated in a credit line to the data. 


\section{Background}

The extensor carpi ulnaris (ECU) muscle-tendon is responsible for ulnar deviation and extension movements of the carpal bones [1]. It contributes to wrist stabilization; isometric contraction of the muscle stabilizes the distal radioulnar joint, especially in pronation, and the ulnocarpal joint in supination [2, 3]. It also contributes to the strong hand-grasping movement $[4,5]$. The term "ECU tendinopathy" was used for describing all painful ECU anomalies resulting from a dysfunctional 6th extensor compartment including subluxation and dislocation [6]. ECU tendinopathy can be one cause of ulnar side wrist pain and it is more prominent in pronation-supination movements against resistance [6-9].

The tendon sheath consisting of thin collagen fibers is primarily responsible for stabilizing the ECU during wrist movements [10]. In supination, flexion, and ulnar deviation within the ulnar groove, the tendon is tense and becomes predisposed to subluxation and dislocation $[11,12]$. "Snapping" (popping) occurs during this dislocation and relocation. Due to this instability and friction between the tendon sheath and ulnar groove, tendinopathy and pain occur. ECU tendon is an important structure that contributes to the dynamic stability of wrist therefore resulting degeneration contributes disruption of distal radioulnar joint and causes wrist instability $[3,6]$.

This study aims to determine the prevalence of ECU snapping through physical examination and provocation tests of participants with no complaints in the general population and to examine tendon subluxation or dislocation by ultrasound in participants with snapping.

\section{Methods}

Informed consent was obtained from the participants before the procedures began. The study was conducted in accordance with the Helsinki Declaration, and approval was obtained from the local ethics committee.

The sample size was based from a previous study [13]. The alpha level was determined as 0.05 , the power as $90 \%$ and the confidence interval as $95 \%$. The current study was determined to include at least 20 participants.

The study was designed as a prospective randomized study. Participants without active wrist complaints who presented to the orthopedics and traumatology outpatient clinic between 2019 and 2020 were included. Randomization was achieved by including participants who applied on Mondays, Wednesdays, and Fridays in the first and third weeks of the month and participants who applied on Tuesdays and Thursdays in the second and fourth weeks. Participants who applied outside of these dates were not included in the study, even if they met the inclusion criteria. Among the 1100 participants; 755 participants without previous upper extremity surgeries, neurological deficits, rheumatologic diseases, open wounds, or active infections in the wrist area and volunteered to participate in the study were evaluated (Fig. 1).

In the forms prepared for the participants, demographic data, recurrent trauma histories, and sports activity levels were evaluated. They were also asked to indicate approximately how much total time they spent daily on the phone (including social media use, messaging, and game playing), on the computer (mouse use, game playing), and on the game console (joystick use).

For sports activity levels, regular activities for six months or longer were evaluated for sports in which upper extremity activity is intense (including tennis, table tennis, badminton, basketball, volleyball, and bodybuilding).Participants were evaluated independently of their recurrent minor trauma histories, daily housework, and occupational activities other than hobby and sports activities.

After obtaining informed consent from the participants, relevant data were entered into the evaluation forms. A bilateral upper extremity provocation test was performed for ECU tendinopathy. The provocation test was first applied to the participants as a "heart-like test" (Fig. 2). They were asked to hold the dorsum of each hand against each other while their wrists were in flexion and their forearms were supine, and then they were asked to press against themselves with the ulnar sides of their hands at chest level. If a snap was not obtained in this way, the clinician performed a provocation test by forcing ulnar deviation against resistance in flexion and supination (Fig. 3). Participants with snapping during the provocation tests were evaluated with ultrasound to determine if there was subluxation or dislocation of the ECU tendon.

Ultrasounds were performed by one radiologist (MMS) with 35 years of professional experience using linear probe (GE Healthcare Systems, Logiq S8). Participants were positioned on examination chair with wrist at flexion and forearm at supination (simulating provocation test). ECU tendon which leaves sulcus approximately 50-99\% was defined as subluxation, tendon which leaves $100 \%$ of the sulcus and stays completely out of the osseous groove, was defined as dislocation $[1,13]$.

IBM SPSS software (SPSS Inc., Chicago, IL, USA) version 23.0 was used to analyze the data. The distribution of data was evaluated with the Kolmogorov-Smirnov test. Quantitative data that were not normally distributed were evaluated using the Mann-Whitney U test, and Student's t-test was used for normally distributed data. The Chisquare test was used to compare categorical variables. For all tests, $p<0.05$ was considered statistically significant.

\section{Results}

Four hundred and fifteen women and 340 men were included in the study. The average age was 38.7 years 
Neurological deficits

Rheumatologic diseases

Open wounds or Active infections

And Non-volunteered participants were

excluded. $(n=345)$

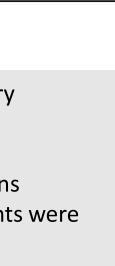

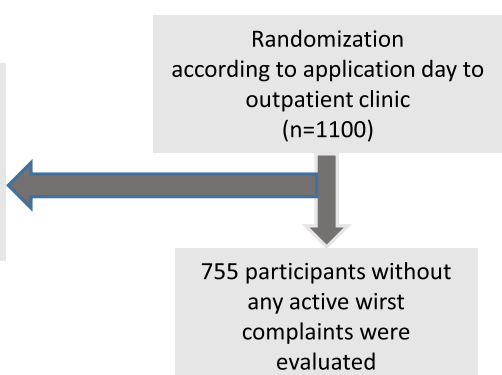

evaluated

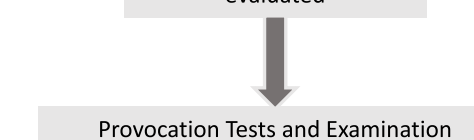

Provocation Tests and Examination

50 participants with Positive Provocation Test

22 participants with

Instability on USG

Subluxation; 19 (\%86.4)

Dislocation; 3 (\%13.6)

28 participants with normal USG

Fig. 1 Evaluation of Participants

(18-66 years). Fifty of the 755 participants $(6.6 \%)$ had snapping. Ultrasounds of these participants in supination, when the ECU tendon is at its most taut position, were evaluated [10, 11]. Subluxation or dislocation was observed in 22 of the 755 participants $(2.9 \%)$ on ultrasound and three (13.6\%) participants had dislocation, 19 (86.4\%) participants had subluxation. The gender, average age, sports

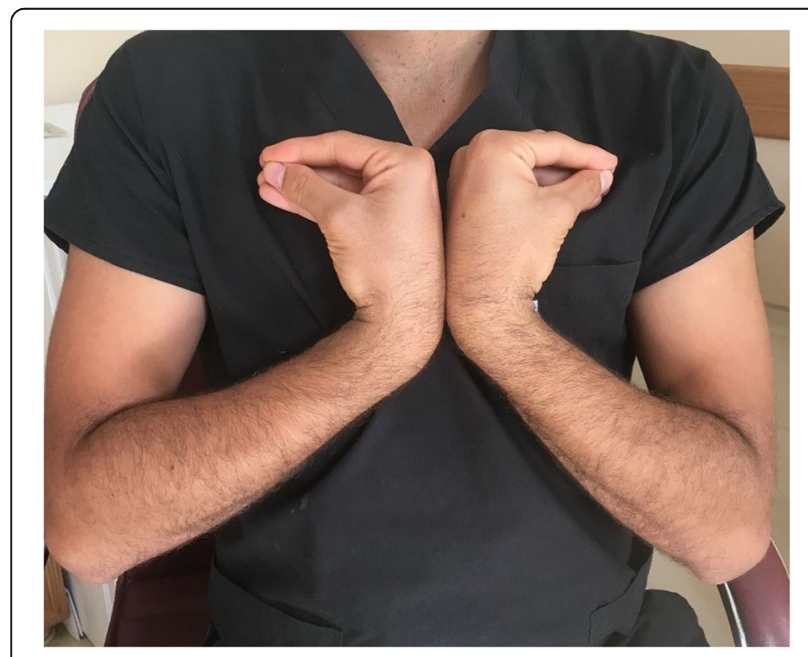

Fig. 2 Participant's "Heart-Shaped" Test

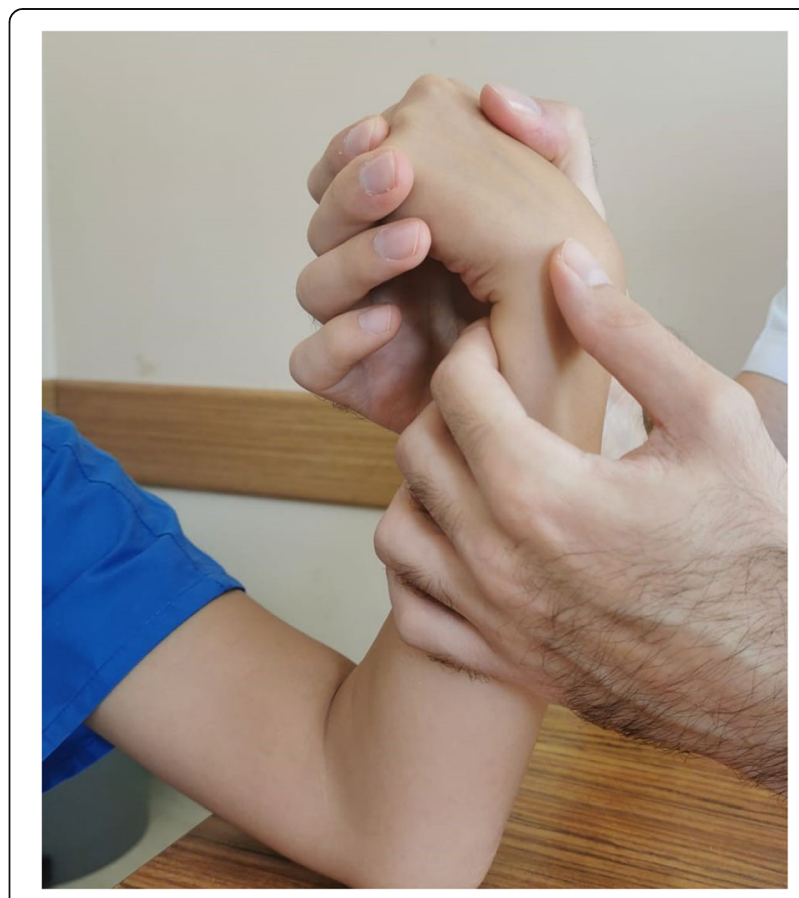

Fig. 3 Provocation of ECU snapping by clinician 
activities, and daily computer and phone activity (including social media use, messaging, and game playing) times of the participants with $(n=22)$ and without $(n=28)$ subluxation or dislocation are presented in Table 1.

It was observed that all 50 of the participants with snapping had significant repetitive trauma and sports activities. It was determined that 21 of the 22 participants who were found to have subluxation or dislocation by ultrasound had more than two hours of daily hobby activity, and significantly more participants had more than two hours of activity compared to the group without subluxation or dislocation.

\section{Discussion}

Extensor carpi ulnaris tendinopathy is the second most common tendinitis of the wrist. Extensor carpi ulnaris tendon subluxation and dislocation causes instability in the distal radioulnar and ulnocarpal joints [3]. Although ECU instability does not cause symptoms in the early period, over time, symptoms, such as swelling, pain sensitivity, weakness in hand-wrist strength, and a clicking or popping sound, begin to occur on the ulnar side. As the tendon sheath is damaged, it no longer functions properly and the symptomatic subluxation or dislocation becomes chronic.

There is a prevalence study in the literature that was based on a population of professional athletes (such as tennis players, rowers, polo players, and golfers) only [13-15]. In the present study, an asymptomatic population was evaluated, and the plan was to determine the prevalence among the general population.

Since the ECU tendon follows a more linear path in forearm pronation than other positions, it is stably located in the ulnar groove [16]. However, in forearm supination, the ECU tendon tends to be pulled to the radial side under the effect of angular force, and it exits from the ulnar groove [16]. In this study, the position in supination, the tensest position in terms of subluxation and dislocation, was evaluated by examining the ECU

Table 1 Comparison of snapping groups according to presence of instability on ultrasound

\begin{tabular}{|c|c|c|c|}
\hline \multicolumn{4}{|c|}{ Snapping ECU Tendon with Provocation Tests $(n=50)$} \\
\hline \multicolumn{4}{|c|}{ Presence of Subluxation or dislocation with USG } \\
\hline & Positive $(n=22)$ & Negative $(n=28)$ & $p$ \\
\hline Age & 39,09 & 36,9 & 0.564 \\
\hline Gender (F/M) & $9 / 13$ & $15 / 13$ & 0.374 \\
\hline $\begin{array}{l}\text { Repetative Trauma } \\
\text { (Yes/No) }\end{array}$ & $2 / 20$ & $3 / 25$ & $>0.999$ \\
\hline Sports Activity (Yes/No) & $4 / 18$ & $5 / 23$ & $>0.999$ \\
\hline $\begin{array}{l}\text { Hoby Activity } \\
\text { (Hours/day) }\end{array}$ & 3.45 & 2.1 & $<0.001$ \\
\hline
\end{tabular}

tendon position in supination of the participants who had snapping.

In their prospective study, Sato et al. evaluated the ECU synergy test under ultrasound guidance in patients with chronic dorso-ulnar wrist pain. They reported that the test is practical and effective in terms of detecting tendon pathologies [17]. When we evaluated the participants in the present study whose provocation test was positive with ultrasound, we found that $44 \%$ had ECU tendon subluxation or dislocation, even though they were asymptomatic. Again, these participants had significantly higher rates of recurrent trauma and sports activities.

There are studies in the literature on the morphology of the ECU groove that investigated the effects of the depth and morphology of the ulnar sulcus on tendinopathy $[18,19]$. Nakashima et al. examined 240 upper extremities and devised four classifications according to sulcus morphology. They stated that $1.3 \%$ were in the classification in which the groove was shallow, and this was observed congenitally regardless of age. In the present study, we evaluated the participants regardless of their ulnar sulcus morphology. Although a flat groove is seen less frequently in the general population, it should be taken into consideration that participants with snapping and instability may have flat or shallow grooves.

According to trends in recent years, we think that the increasing frequency of phone use (messaging with both wrists in ulnar deviation and social media use), the widespread use of game consoles (using joysticks in forearm supination and ulnar deviation), and widespread computer use have increased chronic wrist pain. Burgess et al. stated that approximately $60 \%$ of symptomatic or asymptomatic computer users had distal ECU tendon subluxation or dislocation [20]. In the present study, patients with a minimum of four hours of daily computer use were evaluated. We did not make any limitations when evaluating the daily hobby activity duration. This study found that in participants with snapping, those with an activity duration of more than two hours had statistically significant ECU subluxation or dislocation on ultrasound. Likewise, we found that all but one $(95.5 \%)$ of the participants with ECU subluxation or dislocation had a hobby activity habbit of more than two hours per day.

The limitations of this study include the fact that the participants were evaluated independently of ulnar sulcus morphology. Another limitation is that the traumatizing effects of their daily professional activities on the wrist were not evaluated. Although the provocation test was negative it should be kept in mind that mild, asymptomatic subluxation or dislocation, which could theoretically be seen on ultrasound might be evident in the 705 participants. 
There is no study on prevalence in the literature, and there is a limited number of published data in the past based on studies involving only professional athletes. We think that this study will contribute to the literature in terms of being a study that represents a technologydependent asymptomatic population in daily life.

\section{Conclusions}

This is a randomized prospective study with a large number of participants. Based on these features, we think it will contribute to the literature in terms of evaluating the contribution of technological devices, such as computers, smartphones, and game consoles, which are indispensable parts of daily life, to chronic wrist pain and the prevalence of ECU snapping in the asymptomatic population.

\section{Acknowledgements}

Authors would like to thank Dr. Mehmet Mutlu Samancioglu for ultrasonographic evaluation of participants.

\section{Authors' contributions}

Both authors (FE and TO) contributed equally to the study. Both authors read and approved the final manuscript.

\section{Funding}

The authors received no financial support for the research, authorship, and/ or publication of this article.

\section{Availability of data and materials}

The datasets used and/or analysed during the current study are available from the corresponding author on reasonable request.

\section{Declarations}

Ethics approval and consent to participate

All procedures performed in studies involving human participants were in accordance with the ethical standards of the institutional and/or national research committee and with the 1964 Helsinki declaration and its later amendments or comparable ethical standards. Informed consent was obtained from the participants before the procedures began. This study was prospectively registered to ethical board of The Gaziosmanpasa University Medical Faculty approval and grant number of the study is 19-KAEK-045.

\section{Consent for publication}

Informed consent was obtained from all individual participants included in the study.

\section{Competing interests}

The authors declare that they have no competing interests" in this section.

\section{Author details}

'Department of Orthopaedics and Traumatology, Cesme Alpercizgenakat State Hospital, 35930 Izmir, Turkey. ${ }^{2}$ Department of Orthopaedics and Traumatology, Gaziosmanpasa University, Tokat, Turkey.

Received: 12 February 2021 Accepted: 15 April 2021

Published online: 26 April 2021

\section{References}

1. Garcia-Elias M. Tendinopathies of the extensor carpi ulnaris. Handchir. Mikrochir. Plast. Chir. 2015;47:281-289.

2. Melone PJ Jr, Polatsch DB, Pallotta A. et al. Principles and practice of wrist surgery. Philadelphia: Springer; 2010:185-197.
3. Salva-Coll G, Garcia-Elias M, Leon-Lopez MM et al. Role of the extensor carpi ulnaris and its sheath on dynamic carpal stability. J Hand Surg Eur Vol. 2012; 37:544-548

4. Green DP, Hotchkiss RN, Pederson WC. Green's Operative Hand Surgery. 7th ed. Philadelphia: Elsevier/Churchill Livingstone; 2017:641-642.

5. Williams PL, Bannister LH, Berry MM et al. Gray's Anatomy: The anatomical basis of clinical practice. 40th ed. London: Churchill Livingstone; 2008:831-836.

6. Buterbaugh GA, Brown TR, Horn PC. Ulnar-sided wrist pain in athletes. Clin Sports Medicine. 1998;17:567-583.

7. Kaiser Peter, Haug Luzian, Gabl Markus, Rudisch Ansgar, Klauser Andrea and Rohit Arora. Mid-term outcome (11-90 months) of the extensor retinaculum flap procedure for extensor carpi ulnaris tendon instability. Arch Orthop Trauma Surg. 2019; 139(9): 1323-1328.

8. Rettig AC. Athletic injuries of the wrist and hand: part II: overuse injuries of the wrist and traumatic injuries to the hand. Am J Sports Med. 2004;32:262-273.

9. Wang C, Gill TJ, Zarins B et al. Extensor carpi ulnaris tendon rupture in an ice hockey player: a case report. Am J Sports Med. 2003;31:459-461.

10. Kauer JM. The distal radioulnar joint. Anatomic and functional considerations. Clin Orthop Relat Res. 1992;275:37-45.

11. Allende C, Le Viet D. Extensor carpi ulnaris problems at the wrist classification, 1 surgical treatment and results. J Hand Surg Br. 2005;30:265-72.

12. Inoue G, Tamura Y. Recurrent dislocation of the extensor carpi ulnaris tendon. Br J Sports Med. 1998;32:172-174.

13. Sole JS, Wisniewski SJ, Newcomer KL, Maida E, Smith J. Sonographic evaluation of the extensor carpi ulnaris in asymptomatic tennis players. American Academy of Physical Medicine and Rehabilitation. 2015;7:255-263.

14. Stathopoulos IP, Raptis K, Efstathios GB, Spyridonos SG. Recurrent dislocation of the extensor carpi ulnaris tendon in a water-polo athlete. Trauma Mon. 2016;21:e19551.

15. Yuji Tomori, Mitsuhiko Nanno, Shinro Takai. Recurrent Dislocation of the Extensor Carpi Ulnaris Tendon with Ulnar-Sided Triangular Fibrocartilage Complex Injury in an Ice Hockey Player: A Case Report. J Nippon Med Sch. 2020 9:87(4):233-239.

16. Petchprapa CN, Meraj S, Jain N. ECU tendon "dislocation" in asymptomatic volunteers. Skeletal Radiol. 2016:45:805-812.

17. Sato J, Ishii Y, Noguchi H. Diagnostic performance of the extensor carpi ulnaris (ECU) synergy test to detect sonographic ECU abnormalities in chronic dorsal ulnar-sided wrist pain. J Ultrasound Med. 2016;35:7-14

18. Iorio ML, Bayomy AF, Huang Jl. Morphology of the extensor carpi ulnaris groove and tendon. J Hand Surg Am. 2014;39:2412-2416

19. Nakashima T, Hojo T, Furukawa H. Deep and shallow forms of the sulcus for extensor carpi ulnaris. J Anat. 1993:183:635-638.

20. Burgess RA, Pavlosky WF, Thompson RT. MRI-identified abnormalities and wrist range of motion in asymptomatic versus symptomatic computer users. BMC Musculoskelet Disord. 2010;11:273-278.

\section{Publisher's Note}

Springer Nature remains neutral with regard to jurisdictional claims in published maps and institutional affiliations.
Ready to submit your research? Choose BMC and benefit from:

- fast, convenient online submission

- thorough peer review by experienced researchers in your field

- rapid publication on acceptance

- support for research data, including large and complex data types

- gold Open Access which fosters wider collaboration and increased citations

- maximum visibility for your research: over $100 \mathrm{M}$ website views per year

At $\mathrm{BMC}$, research is always in progress.

Learn more biomedcentral.com/submission 